\title{
Corrigendum: Re-evaluating the Malawian Farm Input Subsidy Programme
}

Joseph P. Messina, Brad G. Peter and Sieglinde S. Snapp

Nature Plants 3, 17013 (2017); published online 6 March 2017; corrected 13 March 2017.

In the version of this Article originally published, the map in Fig. 1 showed Lake Chiuta in the wrong position. Lake Chiuta is actually situated along the southeast border of Malawi. This has now been corrected in all versions of the Article. 